\title{
Los beneficios tributarios como mecanismos para incentivar la donación de alimentos en supermercados en el área metropolitana de Lima, Perú ${ }^{1}$
}

\author{
Stefany Fabiola Lozano Requelme $e^{2}$ \\ Martha Rosa Santillan Valderrama ${ }^{3}$ \\ Kelly del Rosario Yactayo Melo ${ }^{4}$
}

Recibido: 11 de febrero de 2018

Aprobado: 1 de abril de 2018

Clasificación JEL: H23, H30

\section{Resumen}

En Perú, hasta inicios de 2016, los alimentos con fechas próximas de vencimiento, a pesar de que se encontraran en buen estado, no salían a la venta al público ni tampoco eran donados a entidades como bancos de alimentos;

1 Este trabajo fue reconocido como uno de los mejores en el "III Congreso Latinoamericano de Estudiantes de Contaduría y Administración -CONTAD 2017". Ese evento fue organizado por la Asociación Latinoamericana de Facultades y Escuelas de Contaduría y Administración -ALAFEC y se desarrolló en la Universidad de Medellín, en mayo de 2017. Su publicación en la revista Activos es parte del reconocimiento; no está disponible en otra fuente digital.

Citar como: Lozano, S. F., Santillán, M. R. y Yactano, K. (2019). Los beneficios tributarios como mecanismos para incentivar la donación de alimentos en supermercados en el área metropolitana de Lima, Perú. Revista Activos, 16(30), 5578. DOI: https://doi.org/10.15332/25005278.5060

2 Universidad Nacional Mayor de San Marcos, Lima, Perú. Correo electrónico: stefany.lozano@unmsm.edu.pe

3 Universidad Nacional Mayor de San Marcos, Lima, Perú. Correo electrónico: martha.santillan@unmsm.edu.pe

4 Universidad Nacional Mayor de San Marcos, Lima, Perú. Correo electrónico: kelly.yactayo@unmsm.edu.pe 
esto porque ambas operaciones eran consideradas como operaciones gravadas. En ese sentido, las empresas con el fin de poder recuperar algo del gasto en el que incurrieron en la compra de dichos alimentos debían destruirlos, una medida opuesta a una lógica económica racional, así como al cumplimiento de los Objetivos de Desarrollo Sostenible ${ }^{5}$ (ODS). El objetivo de este trabajo fue determinar si los beneficios de la reforma tributaria peruana de 2016 funcionaron de manera eficaz como mecanismo de incentivo para la donación de alimentos en los supermercados que se encuentran en al área metropolitana de Lima, Perú. Para esta investigación se empleó un enfoque mixto, de tipo descriptivo-explicativo a partir de la comparación de marcos normativos, con el cual se buscó clarificar los alcances fiscales y parafiscales de la indicada norma tributaria en el Perú y su impacto en pro del desarrollo social y los efectos que tiene como medida de responsabilidad social.

Palabras clave: tributación, donación de alimentos, objetivos de desarrollo sostenible, responsabilidad social, beneficios tributarios.

\title{
Tax benefits as mechanisms to encourage the donation of food in supermarkets in the metropolitan area of Lima, Perú
}

\begin{abstract}
In Peru, until the beginning of 2016, foods with upcoming expiration dates, even though in good condition, did not go on sale to the public, nor donated to entities such as food banks, this because both operations were considered by the Peruvian Income Tax Law as sales in a strict sense, that is, in the light

5 La propuesta de 17 Objetivos de Desarrollo Sostenible (ODS) para el 2030, son metas y planes de acción con la visión de combatir la pobreza en sus múltiples dimensiones a través de esfuerzos mundiales, regionales, nacionales y locales. Discutida oficialmente en la Cumbre de Desarrollo Sostenible realizada en septiembre del 2015.
\end{abstract}


of Peruvian law they are taxed operations. In this sense, in order to recover some of the expenditure incurred in the purchase of such food, the companies had to destroy food, a measure opposed to rational economic logic, as well as compliance with the Sustainable Development Goals (SDG). At the end of 2016, a tax reform was approved, which included the creation of a tax deduction for food donation. This paper analyzes the effects of said norm, taking as a reference the Colombian proposal contained in the so-called "Anti-food Waste Law to Fight Hunger in Colombia". The objective of this paper is to determine if the tax benefits of the Peruvian regulations function effectively as an incentive mechanism for food donation in supermarkets located in the Metropolitan Area of Lima. The present research work uses a qualitative and quantitative approach, of descriptive - explanatory type from the comparison of normative frameworks, with which it is sought to clarify the fiscal and parafiscal scope of the indicated tax norm in Peru and its impact in pro of social development and the effects it has as a social responsibility measure.

Keywords: Taxation, food donation, sustainable development goals, social responsibility, tax benefits.

\section{Introducción}

El presente trabajo analizó los beneficios tributarios otorgados por la Ley 30298 que genera la donación de alimentos en los supermercados, ya que en el Perú existen innumerables trabas y regulaciones legales, las cuales provocan que las empresas prefieran destruir los alimentos bajo el marco normativo aplicable, pues les resulta menos complicado y costoso, para efectos tributarios, que donarlos. Es por ello que esta investigación se centró en el análisis de los beneficios tributarios, ya que siendo incentivos otorgados a las empresas por parte del Estado, los mismos ayudan al crecimiento y desarrollo del país, consiguiendo objetivos económicos y sociales que apunten a una mejor calidad de vida de la población en general. 
Es importante resaltar que a nivel empresarial las decisiones de las transacciones tienen una importante cuota que se decide acorde a la optimización tributaria, en ese sentido, queda en evidencia que el rol de la tributación juega un papel muy importante en el planeamiento y dirección empresarial.

La presente investigación se enfocó en estudiar la realidad tributaria en Perú, abarcando los puntos de convergencia con la responsabilidad social que debe caracterizar a las normas de derecho ya que son el reflejo de lo que una sociedad necesita en un determinado momento histórico.

Tal como señala la Ley 30498, que promueve la donación de alimentos y facilita el transporte de donaciones en situaciones de desastres naturales, en adelante "Ley de donación de alimentos", lo que se busca es otorgar beneficios tributarios a las empresas, tanto productoras como comercializadoras, que conserven mermas constantes de alimentos para que con ello se puedan donar estos en buen estado a través de entidades intermediarias, como el Banco de Alimentos, lo cual contribuirá con el apoyo a personas y familias de bajos recursos quienes reciben estos alimentos para cubrir sus necesidades de alimentación.

Por lo anteriormente expuesto, dada la vigencia de estas normas tanto en Perú como en países aledaños, resulta justificable esta investigación que pretendió realizar un análisis de los beneficios tributarios como mecanismos de incentivo de donación de alimentos para los supermercados en Lima Metropolitana. La presente investigación proporciona información sobre el posible comportamiento de las empresas con base a la Ley 30498 para que futuras investigaciones puedan tomarla como referencia.

Por ello, cuando se formuló el problema de investigación, se buscó la respuesta a la siguiente pregunta: ¿ de qué manera los beneficios tributarios funcionan como mecanismo de incentivo en la donación de alimentos en los supermercados en Lima Metropolitana?

En ese sentido, para responder a la pregunta de investigación, se tuvo como objetivo general el determinar si los beneficios tributarios según la 
Ley 30498 funcionan como mecanismo de incentivo en la donación de alimentos de los supermercados en Lima Metropolitana.

Para lograr dicha respuesta, se tomaron dos objetivos específicos, que fueron: a) dar a conocer las donaciones de los supermercados al Banco de Alimentos Perú que posteriormente serían distribuidos a los beneficiarios y, b) comparar los beneficios tributarios de la Ley 30498 en Lima Metropolitana con respecto al Proyecto de Ley antidesperdicios contra el hambre en Colombia.

Al respecto, se manejó como hipótesis general que los beneficios tributarios señalados en la Ley 30498 funcionan positivamente como mecanismo de incentivo en la donación de alimentos de los supermercados en Lima Metropolitana.

Ello, en función a que a) la aplicación de la Ley 30498 promueve las donaciones y la posterior creación de bancos de alimentos, permitiendo una mejor distribución a los beneficiarios y que, b) la comparación de la Ley 30498 y el Proyecto de Ley PDA muestran nuevas alternativas a proponer para el régimen normativo peruano.

De esta manera, a través de las diversas encuestas realizadas a los gerentes de los supermercados de Lima Metropolitana se buscó demostrar la veracidad de las hipótesis aquí planteadas.

\section{Metodología de la investigación}

El presente trabajo no presentó población debido a que fue una investigación que analizó los datos recopilados de las diferentes fuentes fiables, como entrevistas a gerentes de los supermercados de Lima Metropolitana.

Esta investigación tuvo un enfoque cualitativo y cuantitativo, de tipo descriptivo-explicativo, porque se basó en analizar si los beneficios tributarios funcionan como mecanismo de incentivos de donación de alimentos de los supermercados en Lima Metropolitana y así poder interpretar los 
resultados y saber si se logra un incremento de donaciones de alimentos por parte de los supermercados, producto de la reciente Ley 30498.

Se recogieron datos de la Superintendencia Nacional de Aduanas y de Administración Tributaria, Sociedad de Comercio Exterior, consultoría internacional CCR y normativa legal tanto colombiana como peruana, que fueron comparadas.

Para determinar las estimaciones de la donación de alimentos, se aplicó el método regla de tres simple, tomando como base la aproximación de renta neta por supermercado determinado por Jorge Lazarte, gerente de asuntos corporativos Inretail Perú.

\section{Marco teórico}

La política de donación de alimentos tiene sus antecedentes en la hambruna europea que ocasionó la Segunda Guerra Mundial (Blondet y Montero, 1995). Los Estados Unidos, que se encontraban en un período de expansión agrícola e industrial, orientaron sus excedentes de producción a este continente estableciendo una política asistencial que quedaría consagrada en el llamado "Programa de Alimentos para la Paz" o Ley Pública 480. Conforme la economía europea se fue recuperando, la política norteamericana de donaciones alimentarias se orientó crecientemente hacia los países subdesarrollados (Lizarzaburú, 1989).

El primer banco de alimentos se estableció en Estados Unidos en 1967 (ST. Mary's Food Bank Aliance) ${ }^{6}$ en Arizona, y desde entonces y hasta el día de hoy, miles de bancos de alimentos se han creado a lo largo y ancho de todo el mundo.

6 Objetivo 2: abrir nuevos caminos para la nutricion, la agricultura y los sistemasalimentarios, Cronica de la ONU. Recuperado de: http://www.firstfoodbank. org/ 
El tema del hambre no es nuevo, Josué de Castro (1951) aporta una luz singular a la complejidad del fenómeno de la desnutrición en su obra Geopolítica del hambre. Publicada por primera vez en 1951, esta obra despertó la consciencia del mundo sobre la terrible calamidad que es el hambre, contribuyendo, además, a crear una concepción enteramente nueva de los problemas del subdesarrollo.

El Comité de Derechos Económicos, Sociales y Culturales ha definido el alcance del contenido esencial del derecho a la alimentación así: “[...] la garantía del derecho a la alimentación se relaciona con el concepto de seguridad alimentaria y nutricional esbozado en el Plan de Acción de la Cumbre Mundial sobre la Alimentación" (Arteaga, 2010, p. 13).

Actualmente se cuenta con el concepto de responsabilidad social empresarial, definida como el compromiso que asume una empresa para contribuir al desarrollo económico sostenible por medio de la colaboración con sus empleados, sus familias, la comunidad local y la sociedad, con el objeto de mejorar la calidad de vida (World Business Council for Sustainable Development, 1999), aportando a Objetivos del Desarrollo Sostenible (ODS), los cuales consisten en 17 objetivos globales, presentados por los Estados miembros de la ONU en conjunto con ONG y ciudadanos de todo el mundo, con el fin erradicar la pobreza, proteger el planeta y asegurar la prosperidad para todos como parte de una nueva agenda de desarrollo sostenible.

Los ODS 2, abren las puertas a una amplia gama de puntos de partida en materia de políticas y programas para mejorar la nutrición a través de la agricultura. No obstante, en lo que respecta al seguimiento y la evaluación de la nutrición, los parámetros son más estrictos ${ }^{7}$.

7 Objetivo 2: abrir nuevos caminos para la nutrición, la agricultura y los sistemas alimentarios, Crónica de la ONU, Recuperado de: https://unchronicle.un.org/es/ article/objetivo-2-abrir-nuevos-caminos-para-la-nutrici-n-la- agricultura-y-lossistemas-alimentarios 


\section{Marco legal}

Marco normativo en Perú: ley que promueve la donación de alimentos y facilita el transporte de donaciones en situaciones de desastres naturales

Después de conocer más sobre el marco teórico, se realizó un enfoque sobre el marco legal, comenzando con lo dispuesto en la Declaración Universal de Derechos Humanos que señala lo siguiente: "Artículo 25. (1) Toda persona tiene derecho a un nivel de vida adecuado que le asegure, así como a su familia, la salud y el bienestar, y en especial la alimentación, el vestido...”.

De otro lado, el Pacto Internacional de Derechos Económicos, Sociales y Culturales (PIDESC) y su Protocolo Facultativo, firmado y ratificado por Perú, regulan la protección de los derechos económicos, sociales y culturales (DESC); este pacto internacional señala lo siguiente:

Artículo 11. (1) Los Estados partes en el presente pacto reconocen el derecho de toda persona a un nivel de vida adecuado para sí y su familia, incluso alimentación, vestido y vivienda [..]. (2) Los Estados partes en el presente pacto, reconociendo el derecho fundamental de toda persona a estar protegida contra el hambre, adoptarán, individualmente $[\ldots]^{9}$.

Los artículos mencionados sustentan y amparan el derecho a una alimentación adecuada haciendo que los países intervinientes incorporen dentro de sus políticas de Estado medidas legislativas que contribuyan a hacer frente a la problemática de la falta de alimentación, ya que lo anterior constituye un derecho a nivel de sus constituciones políticas.

8 Asamblea General de la ONU. (1948). "Declaración Universal de los Derechos Humanos” (217 [III] A). París. Recuperado de: http://www.un.org/en/universaldeclaration-human-rights/

9 Recuperado de: http://www.ohchr.org/SP/ProfessionalInterest/Pages/CESCR. aspx 
Debido a ello se encontró dentro de la Carta Magna del Perú, el Principio de Reserva de Ley, que en su artículo 74 señala lo siguiente: "Artículo 74. (...) El Estado, al ejercer la potestad tributaria, debe respetar los principios de reserva de la ley, y los de igualdad y respeto de los derechos fundamentales de la persona [...]".

Esto significa que la Constitución peruana no le da un tratamiento distinto a la facultad de crear, modificar o derogar un tributo, sino que también exige la observancia del principio de reserva de ley cuando se trata de establecer beneficios tributarios.

De acuerdo con el Tribunal Constitucional en la STC 0042-2004-AI1, los beneficios tributarios son tratamientos normativos que implican por parte del Estado una disminución total o parcial del monto de la obligación tributaria o la postergación de la exigibilidad de dicha obligación (Villanueva, 2011).

Una de las medidas que hace frente a la problemática mencionada es la donación de alimentos, que consiste en actos por los cuales los donantes disponen a título gratuito productos alimenticios no perecibles definidos como: cualquier sustancia comestible, ya sea cruda, procesada, preparada o cocinada, hielo, bebidas, ingredientes que cumplen con todos los requisitos de calidad legal correspondiente y que, si bien no pueden ser comercializados en el mercado por razones de apariencia, frescura, madurez, tamaño u otras condiciones equivalentes, la ley que promueve la donación de alimentos y facilita el transporte de donaciones en situaciones de desastres naturales (Ley 30498, 2016), mencionan dos formas de donaciones, que son:

a. Las donaciones por pérdida de valor comercial, son donaciones de alimentos en buen estado que hubieran perdido valor comercial y se encuentren aptos para el consumo humano, a efectos de que, a partir del tercer año de la entrada en vigencia de esta ley, los almacenes de alimentos y supermercados donen la totalidad de los alimentos que tengan esta condición, quedando prohibida la destrucción de los mismos con la finalidad de contribuir a satisfacer las necesidades alimentarias de la población económicamente más vulnerable. 
b. Las donaciones durante estado de emergencia, las donaciones y los servicios gratuitos para atender a la población afectada de las localidades declaradas en estado de emergencia por desastres producidos por fenómenos naturales, siendo aplicable durante el plazo de dicho estado de emergencia.

Las donaciones de alimentos por empresas son recolectadas, administradas y distribuidas por bancos de alimentos, que son organizaciones sin fines de lucro basadas en el voluntariado y cuyo objetivo es rescatar alimentos, principalmente no perecibles, de la sociedad y redistribuirlos entre las personas necesitadas impidiendo su desperdicio o mal uso.

Los bancos de alimentos son intermediarios, debido a que entregan la comida recaudada a instituciones caritativas y de apoyo social, y estas últimas son la que tienen el contacto con los beneficiarios de la donación.

A través de esta asociación (Banco de Alimentos Perú) lo que se busca es rescatar los alimentos que están en perfecto estado, que sean aptos para el consumo humano y que por distintos motivos ya no son comercializables, para que no terminen en la basura (Hernández, 13 de septiembre de 2013). El donante y las entidades perceptoras están sujetas a responsabilidades civiles o penales por los daños causados en el caso de que se probara la existencia de culpa grave o dolo imputable al momento de la entrega efectiva de la donación y recepción de productos alimenticios en donación hasta la entrega a los beneficiarios, respectivamente.

Considerando la entrega de los alimentos a los beneficiarios, tales productos se distribuirán de manera gratuita, sin embargo, no por esto se pierde la protección del derecho del consumidor de acuerdo a lo señalado en la Ley 29571 (Código de protección y defensa del consumidor). El Estado defiende el interés de los consumidores y usuarios para garantizar el derecho a la información sobre los bienes y servicios que se encuentran a su disposición en el mercado. Asimismo, vela en particular por la salud y la seguridad de la población (Constitución Política del Perú, art. 65). 
El Estado, para incentivar la donación de alimentos, aplica como beneficio tributario el reconocimiento de los gastos incurridos para llevar a cabo la donación como gastos deducibles para efectos de la determinación del impuesto a la renta hasta el límite del $10 \%$ de la renta neta de tercera categoría, señalado en el inciso x) del artículo 37 y en el inciso b) del artículo 49 de la Ley del Impuesto a la Renta, siempre que tales servicios tengan como finalidad la atención de la población afectada por desastres producidos por fenómenos naturales.

No considerándose la donación como venta gravada para efectos de la ley del impuesto general a las ventas e impuesto selectivo al consumo, la entrega de bienes efectuada a título gratuito por los donantes a las entidades perceptoras de donaciones calificadas por la Sunat, teniendo un impacto en la determinación del IGV a pagar, ya que para este cálculo se considera el IGV originario de las compras y no el de las transacciones de venta gravada.

Se perdería el beneficio tributario mencionado, si con posterioridad a la donación se identificara que los bienes donados no estuvieron aptos para su consumo, teniendo relación con las responsabilidades civiles o penales que nos describe la norma (Ley 30498, 2016).

Se cuenta con la normativa relacionada a donación de alimentos de países hermanos, en la cual se guarda similitud en muchos de los conceptos, pero a la vez se cuenta con algunas distinciones en el alcance de la conceptualización.

\section{Marco normativo sugerido en Colombia: Proyecto de Ley antidesperdicios contra el hambre}

El Proyecto de Ley 169 del año 2016 de Colombia, denominado "Proyecto de Ley antidesperdicios contra el hambre en Colombia", en adelante, "Proyecto de Ley PDA"; tiene por objeto establecer medidas para reducir las pérdidas o desperdicios de alimentos. 
Su ámbito de aplicación recae en todos los actores de la cadena de suministro de la red de valores relacionados directa o indirectamente con el sector de alimentos.

Para efectos de la Ley PDA se considerará como a toda sustancia elaborada, semielaborada, bruta, natural o artificial, cultivada o no, fresca o conservada, perecedera o no perecedera, que se destina al consumo humano.

Estos alimentos tendrán como destinatarios en general a todo ser humano que por sus condiciones de vida padezca de los sufrimientos de la desnutrición y del hambre.

Ahora, con respecto a los beneficios tributarios que ofrece esta propuesta legislativa, la donación de alimentos consiste en la entrega de todo alimento que haya dejado de tener posibilidad de comercialización y que se pueda aprovechar para consumo humano (sobre todo aquellos que cubren la canasta familiar), sin costo alguno a los bancos de alimentos, sociedades sin ánimo de lucro y demás entidades autorizadas y registradas, so pena de las sanciones a que haya lugar.

Con respecto al Impuesto al Valor Agregado, en adelante "IVA", estarán exentos todos los contribuyentes que realicen donaciones a bancos de alimentos provenientes de sus pérdidas y desperdicios, según los criterios y las condiciones definidas por el estatuto tributario en donaciones y contribuciones. Tendrán estas personas jurídicas o naturales derecho a deducir de su renta el $175 \%$ del valor invertido en dichas donaciones en el período gravable en que se realizó la inversión. Esta deducción no podrá exceder del cuarenta por ciento $40 \%$ de la renta líquida, determinada antes de restar el valor de la inversión.

Es decir, los contribuyentes podrán optar por la alternativa de deducir el $175 \%$ del valor de las donaciones efectuadas a bancos de alimentos a que se refiere este artículo, siempre y cuando se destinen exclusivamente a donaciones y cuando el beneficio supere el valor máximo deducible en el año en que se realizó la inversión o la donación, el exceso podrá solicitarse 
en los años siguientes hasta agotarse, aplicando el límite del $40 \%$ a que se refiere el inciso primero y el parágrafo primero del artículo referente.

\section{Resultados y discusión}

\section{Análisis, interpretación y discusión de resultados}

Haciendo referencia a la primera hipótesis, se puede señalar que el propósito de la ley de donación de alimentos es hacerle frente a una situación injusta que vincula, de un lado, a la creciente necesidad social de aquellos que sufren hambre en el país, y, de otro lado, a aquellas empresas que tienen pérdidas normales por el giro de su negocio, pero no tenían una opción diferente a la de la destrucción de los mismos para que frente a la Administración Tributaria (Sunat) puedan ser deducibles y no considerados como una venta.

Debemos resaltar que en el Perú la pérdida total de alimentos como porcentaje de la oferta interna, según la Sociedad de Comercio Exterior (Comex), asciende al $8.7 \%$, más de tres puntos por encima del promedio mundial, colocándolo como el sexto país de la región con mayor pérdida de alimentos, situación preocupante, tomando en cuenta que más de 2 millones de peruanos (de un total de casi 31.5 millones de habitantes según el INEI al año 2016) sufren de subalimentación y más de 500000 niños padecen todavía de desnutrición crónica. Frente a esto, los supermercados, aquellos con mayor cantidad de alimentos de consumo diario, desechan más de 7 millones de toneladas de alimentos equivalentes a 500 millones de soles al año, alimentos por vencer o con defectos de presentación.

El descarte de estos alimentos se hace porque ya no tienen un valor comercial para las empresas, pero sí tienen un valor social, ya que no solo están en buen estado, sino que son aptos para el consumo humano. Estos alimentos lejos de ser únicamente desmedros, se pueden donar y pueden mejorar la situación de inseguridad alimentaria y nutricional en la que se encuentran cerca de 2 millones de peruanos. Lo anterior permitiría también reducir el gasto de alimentos que realizan las organizaciones no 
lucrativas, que benefician a miles de niños, adolescentes, adultos mayores, mujeres víctimas de la violencia, personas con discapacidad o que sufren de enfermedades graves. La ley de donación de alimentos tiene como propósito que para el 2019, en el país, no se permitirá nunca más que se arrojen los alimentos o se destruyan para que puedan ser deducibles tributariamente.

Cencosud, con el fin de apoyar y fortalecer la gran labor que realiza el Banco de Alimentos del Perú, firmó un convenio de colaboración y donación de alimentos en el año 2016, el cual benefició con la entrega de alimentos a más de 20 mil personas de las instituciones asociadas al programa, como centros educativos, albergues infantiles, comedores populares y asilos para adultos mayores. El valor alimenticio de estos productos ayudará a mejorar los indicadores nutricionales de las personas beneficiarias, contribuyendo de manera directa a la lucha contra la desnutrición y anemia en el país ${ }^{10}$.

Por otro lado, desde mayo del 2016 Hipermercados Tottus ha iniciado un programa de donación de alimentos para la población de escasos recursos, a través de un convenio con el Banco de Alimentos del Perú. Así, esta empresa donará frutas y verduras aptas para el consumo, pero que por estética o cercanía a la fecha de vencimiento dejan de ser comercializables. El Banco de Alimentos recogerá las donaciones todas las semanas en su Centro de Distribución de Huachipa ${ }^{11}$.

Tottus comenta también que 300 millones de soles se desperdician al año en alimentos que son desechados por defectos en su empaque o en

10 Ecomedia (14 de julio de 2016). Recuperado de: http://ecomedia.pe/ noticia/1694656/cencosud-se-une-al-banco-alimentos-peru-beneficiar-mas-20mil-ninos- adultos

11 Mercadonegro (11 de mayo de 2016). Recuperado de: http://www. mercadonegro.pe/tottus-convenio-banco-alimentos-ayudar-personas-bajosrecursos/ 
su presentación, con lo cual definitivamente era mucho más responsable redireccionar y sobre todo recuperar las mermas ${ }^{12}$.

Con base en lo mencionado y continuando con la explicación, para la deducibilidad del gasto se dará un pequeño repaso de cómo funcionan las reglas de impuestos en el país. Respecto a los montos, se ha tomado como base el monto de renta aproximada de 50 millones de soles que recibe anualmente cada supermercado en Perú, así lo señala Jorge Lazarte, gerente de asuntos corporativos de Inretail.

Figura 1. Evolución supermercados Lima/provincias
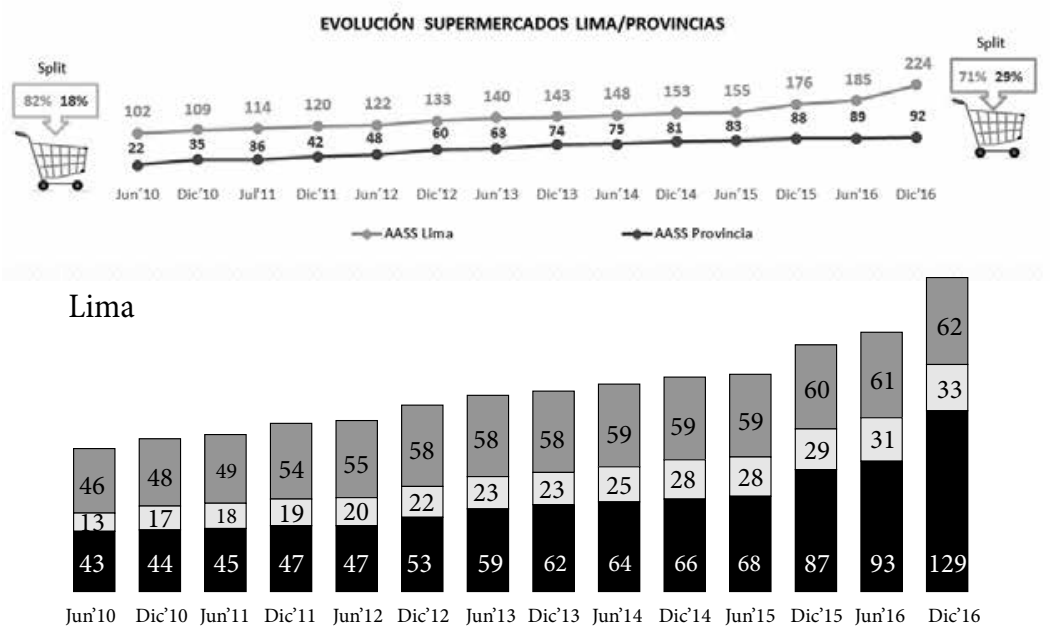

Fuente: Sociedad de Comercio Exterior, consultoría internacional.

Para los dos años previos, se han utilizado montos ascendentes acordes al ritmo de crecimiento del sector retail $^{13}$ en Perú, mostrado por CCR, consultora internacional dedicada al diagnóstico estratégico para decisiones de negocios (PerúRetail, 18 de enero de 2018).

12 Publimetro (10 de mayo de 2016). Recuperado de: http://publimetro. pe/actualidad/noticia-tottus-firma-convenio-donar-alimentos-poblacionesvulnerables-45619

13 Significa venta al detalle o comercio minorista. 
A partir de ello se determina la Tabla 1.

Tabla 1. Crecimiento del sector retail en Perú

\begin{tabular}{c|c}
\hline Año & Renta anual \\
\hline 2015 & 40000000 \\
\hline 2016 & 45000000 \\
\hline 2017 & 50000000 \\
\hline 2018 & 55000000 \\
\hline
\end{tabular}

Fuente: elaboración propia.

Dado los datos mostrados, se proyecta el cálculo del porcentaje de donaciones (tabla 2):

Tabla 2. Estimación de donaciones en Perú*

\begin{tabular}{c|c|c|c|c|c|c|c}
\hline \multicolumn{2}{c|}{} & \multicolumn{2}{c|}{ Sin Ley $\mathbf{3 0 4 9 8}$} & \multicolumn{2}{c|}{ Con Ley 30498 } & \multicolumn{2}{c}{ Comparativo } \\
\hline Año & $\begin{array}{c}\text { Renta } \\
\text { anual** }\end{array}$ & $\begin{array}{c}\text { \% de } \\
\text { donación }\end{array}$ & $\begin{array}{c}\text { Importe } \\
\text { donado }\end{array}$ & $\begin{array}{c}\% \text { de } \\
\text { donación }\end{array}$ & $\begin{array}{c}\text { Importe } \\
\text { donado }\end{array}$ & $\begin{array}{c}\text { Diferencia } \\
\text { del importe } \\
\text { donado }\end{array}$ & $\begin{array}{c}\text { Diferencia } \\
\text { porcentual }\end{array}$ \\
\hline 2015 & 40000000 & 0.6 & 240000 & & & & \\
\hline 2016 & 45000000 & 0.7 & 315000 & & & & \\
\hline 2017 & 50000000 & 0.8 & $\mathbf{4 0 0 0 0 0}$ & 10 & $\mathbf{5 0 0 0 ~ 0 0 0}$ & 4600000 & $\mathbf{1 2 5 0} \%$ \\
\hline 2018 & 55000000 & 0.9 & $\mathbf{4 9 5 0 0 0}$ & 10 & $\mathbf{5 5 0 0 ~ 0 0 0}$ & 5005000 & $\mathbf{1 1 1 1 \%}$ \\
\hline
\end{tabular}

Fuente: elaboración propia.

${ }^{*}$ Se han utilizado los montos máximos esperados para las donaciones.

** Todos los montos presentados son en soles (S/).

Con los datos recopilados, se realizó la proyección del importe donado tomando como base la renta anual de las empresas de retail de alimentos en Perú frente a la nueva Ley 30498, calculando a partir de los estimados anteriores el importe donado aproximado en ambos escenarios sin la Ley 30498 y con la Ley 30498.

Con ello, se realizó un comparativo diferencial usando los porcentajes máximos permitidos en Perú. De esta forma, se observó el posible incremento en las donaciones de alimentos y se notó el considerable resultado 
después de aplicar los porcentajes para ambos escenarios; en ese sentido, se tienen diferencias sustanciales del importe que sería donado, las cuales llevadas a un nivel porcentual, representarían en el nuevo escenario con la Ley 30498, por ejemplo para el año 2017, un incremento equivalente al $1250 \%$ de lo que usualmente se tendería a donar.

Por otro lado, respecto a la segunda hipótesis, una vez calculado el impacto positivo que crea la Ley 30498 mostrado en la primera hipótesis, se conocieron nuevas formas de legislar para comprender y mejorar, mediante un comparativo normativo con Colombia, país de referencia, que desde el 2009 vienen promoviendo la donación a través de los bancos de alimentos.

De la revisión de la Ley 30948 y el proyecto de ley colombiano, se pudieron encontrar puntos de convergencia, pero también diferencias que, de cara a mejorar el marco normativo peruano, se puede reconocer y sugerir sean adicionadas al mismo.

En este sentido, las similitudes encontradas parten de la intención que reflejan ambas de generar un entorno en el que se promueva la donación de alimentos, protección contra el desperdicio de alimentos y donaciones en situaciones de desastres naturales.

La finalidad de ambos documentos procura promover la donación de alimentos para contribuir al desarrollo sostenible de las comunidades desde la inclusión social, la sostenibilidad ambiental y el desarrollo económico en el día a día o frente a desastres naturales.

La Ley 30948 hace referencia a toda persona, natural o jurídica, que esté dispuesta a donar alimentos a las entidades perceptoras, puede ser posible la obtención este beneficio siempre y cuando se entregue la donación de alimentos directamente o a una entidad sin fines de lucro. De manera similar, en la propuesta colombiana, el ámbito es aplicable a todos los actores de la cadena de suministro de alimentos, relacionados directa o indirectamente con el sector de alimentos, identificados como personas naturales o jurídicas, privadas o públicas, nacionales o extranjeras con actividad en Colombia. 
Los beneficiarios de la Ley 30948 son aquellos que reciban la alimentación gratuita ya sea de manera directa $\mathrm{o}$ a través de instituciones que la repartan; en la propuesta colombiana las personas beneficiarias del consumo, acceso y distribución de los alimentos se dan por parte de organizaciones solidarias de desarrollo.

Todo ello con respecto a la parte general de la normativa, sin embargo, para entender los beneficios tributarios que obtendrían las empresas, se realizó un cuadro comparativo (Tabla 3) de elaboración propia entre ambas normativas, centrado en los beneficios tributarios que cada país presenta.

Tabla 3. Comparativo tributario Colombia-Perú

\begin{tabular}{|c|c|c|}
\hline & Colombia & Perú \\
\hline $\begin{array}{l}\text { Nombre de } \\
\text { la ley }\end{array}$ & $\begin{array}{l}\text { Proyecto de ley que crea la } \\
\text { política alimentaria nacional } \\
\text { contra el desperdicio de ali- } \\
\text { mentos, se establecen medidas } \\
\text { para reducir las pérdidas o } \\
\text { desperdicios de alimentos } \\
\text { (PDA) y se dictan otras } \\
\text { disposiciones. }\end{array}$ & $\begin{array}{l}\text { Ley que promueve la donación de } \\
\text { alimentos y facilita el transporte de } \\
\text { donaciones en situaciones de desas- } \\
\text { tres naturales. }\end{array}$ \\
\hline Exoneración & $\begin{array}{l}\text { IVA: } \\
\text { Artículo } 11^{\circ} \\
\text { Estarán exentas de IVA todas } \\
\text { las donaciones realizadas a los } \\
\text { bancos de alimentos. }\end{array}$ & 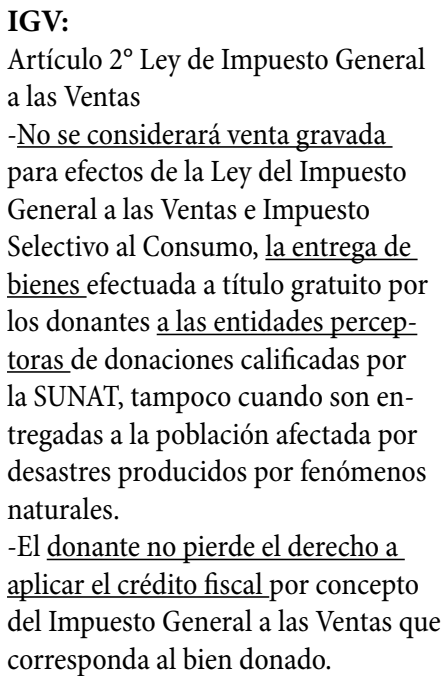 \\
\hline
\end{tabular}




\begin{tabular}{|c|c|c|}
\hline & $\begin{array}{l}\text { Impuesto a la renta: } \\
\text { Artículo } 11^{\circ} \\
\text { Las personas naturales o } \\
\text { jurídicas, privadas o públicas, } \\
\text { nacional o extranjera con } \\
\text { actividad en Colombia que } \\
\text { realicen donaciones a bancos } \\
\text { de alimentos provenientes } \\
\text { de sus pérdidas y desper- } \\
\text { dicios, según los criterios } \\
\text { y las condiciones definidas } \\
\text { por el Estatuto Tributario en } \\
\text { donaciones y contribuciones } \\
\text { tendrán derecho a deducir } \\
\text { de su renta, el ciento setenta } \\
\text { y cinco por ciento (175\%) } \\
\text { del valor invertido en dichas } \\
\underline{\text { donaciones en el período }} \\
\text { gravable en que se realizó la } \\
\text { inversión. Esta deducción no } \\
\text { podrá exceder del cuarenta } \\
\text { por ciento (40\%) de la renta } \\
\text { líquida, determinada antes de } \\
\text { restar el valor de la inversión. }\end{array}$ & $\begin{array}{l}\text { Impuesto a la renta: } \\
\text { Artículo } 37^{\circ} \text {, literal x. } 1 \text { ) Ley de } \\
\text { Impuesto a la Renta. Los gastos por } \\
\text { concepto de donaciones de alimentos } \\
\text { en buen estado que hubieran perdido } \\
\text { valor comercial y se encuentren aptos } \\
\text { para el consumo humano que se rea- } \\
\text { licen a las entidades perceptoras de } \\
\text { donaciones, así como los gastos nece- } \\
\text { sarios que se encuentren vinculados } \\
\underline{\text { con dichas donaciones. La deducción }} \\
\text { para estos casos no podrá exceder del } \\
10 \% \text { de la renta neta de tercera cate- } \\
\text { goría. Tratándose de contribuyentes } \\
\text { que tengan pérdidas en el ejercicio, la } \\
\text { deducción no podrá exceder del } 3 \% \\
\text { de la venta neta del ejercicio. } \\
\text { Las referidas donaciones no son } \\
\text { consideradas transacciones sujetas a } \\
\underline{\text { las reglas de valor de mercado a que }} \\
\text { se refiere el artículo } 32 \text { de la presente } \\
\text { Ley. }\end{array}$ \\
\hline Deducción & $\begin{array}{l}\text { Cuando el beneficio supere } \\
\text { el valor máximo deducible } \\
\text { en el año en que se realizó la } \\
\text { inversión o la donación, el } \\
\text { exceso podrá solicitarse en los } \\
\text { años siguientes hasta agotarse, } \\
\text { aplicando el límite del cuaren- } \\
\text { ta por ciento }(40 \%) \text {. }\end{array}$ & \\
\hline Requisitos & $\begin{array}{l}\text { Requisitos: } \\
\text { Artículo } 11^{\circ} \\
\text { REl Consejo Nacional de } \\
\text { Beneficios Tributarios en } \\
\text { donaciones definirá anual- } \\
\text { mente un monto máximo } \\
\text { total de la deducción prevista } \\
\text { en el artículo 13, así como los } \\
\text { porcentajes asignados de ese } \\
\text { monto máximo total para cada } \\
\text { tamaño de empresa, siguiendo } \\
\text { para ello los criterios }\end{array}$ & $\begin{array}{l}\text { Requisitos: } \\
\text { Artículo } 21^{\circ} \text { literal s) Reglamento de } \\
\text { la Ley de Impuesto a la Renta } \\
\text {-Mediante el acta de entrega y } \\
\text { recepción del bien donado y una } \\
\text { copia autenticada de la resolución } \\
\text { correspondiente que acredite que la } \\
\text { donación ha sido aceptada. } \\
\text {-Mediante el "Comprobante de recep- } \\
\text { ción de donaciones" -Se declararán a } \\
\text { SUNAT las donaciones efectuadas y } \\
\text { el destino. }\end{array}$ \\
\hline
\end{tabular}




\begin{tabular}{l|l|l}
\hline & $\begin{array}{l}\text { y las condiciones de tamaño } \\
\text { de empresa que establezca el } \\
\text { Gobierno nacional. }\end{array}$ & $\begin{array}{l}\text {-Los datos de identificación del } \\
\text { donante. }\end{array}$ \\
& & $\begin{array}{l}\text {-Los datos que permitan identificar } \\
\text { el bien donado, su valor, estado de } \\
\text { conservación, fecha de vencimiento } \\
\text { que figure impresa en el rotulado }\end{array}$ \\
& & $\begin{array}{l}\text { inscrito o adherido al envase o } \\
\text { empaque de los productos perecibles, } \\
\text { de ser el caso, así como la fecha de la } \\
\text { donación. } \\
\text { Artículo } 4^{\circ} \text { de la Ley } 30498: \\
\text {-En el caso de alimentos empaqueta- } \\
\text { dos, los donantes dejarán constancia } \\
\text { en el empaque de los alimentos su }\end{array}$ \\
& $\underline{\text { descripción y fecha de vencimiento. }}$ \\
\hline
\end{tabular}

Fuente: elaboración propia. Normativas colombiana y peruana.

De acuerdo al cuadro anterior, se observa que ambas normas buscan generar beneficios a través de la exoneración de ciertos tributos para las donaciones. Se hace hincapié en que tales donaciones fueron consideradas, en su oportunidad, como operaciones gravadas o como operaciones equivalentes a una venta, y no como una donación que es a título gratuito.En ese sentido, se focaliza el comparativo en tres grandes aspectos tributarios, los cuales son los siguientes:

\section{a. Impuesto al Valor Agregado (IVA) o Impuesto General a las Ventas (IGV)}

En este aspecto, este tributo exonera al acto de donación de este impuesto, debido a que, por la naturaleza de las normas presentadas, que buscan invitar a las empresas y a la población a donar alimentos en lugar de destruirlos o desperdiciarlos, se requieren las facilidades para que los donantes entreguen este material a quienes más lo necesitan sin que sea considerada esta operación como una actividad a la que se le deba presumir un precio o valor en el mercado que esté sujeto a una tasa presunta. 


\section{b. Impuesto a las ganancias o impuesto a la renta}

Sin embargo, los porcentajes de beneficios tributarios marcan la diferencia entre ambos documentos, ya que en la propuesta colombiana podría aprovecharse hasta el $175 \%$ del valor de las donaciones dirigidas a los bancos de alimentos, y hasta el $40 \%$ de las rentas líquidas; sin embargo, en la Ley 30948 solo es permitido en el mejor de los escenarios la deducción del 10 $\%$ de las rentas netas del ejercicio de la empresa, colocándole un límite al apoyo que se brindará y no promoviendo el mayor apoyo como lo hace la propuesta colombiana.

\section{c. Requisitos para el sustento}

En este aspecto, se tienen dos diferencias importantes. La primera, por que quienes proponen los requisitos para poder demostrar que las donaciones fueron efectuadas, en Perú, están dados en la misma norma, sin embargo en Colombia, se propone un estudio más especializado de los mismos, mediante la propuesta de los requisitos estipulados por el REI Consejo Nacional de Beneficios Tributarios acorde a los tamaños de empresas que el Gobierno nacional plantee.

Es en este tenor que se encuentra la segunda diferencia importante que está constituida por los montos máximos deducibles según cada nivel o tamaño de empresa que el Gobierno determine. En Colombia, acorde a la propuesta de Ley PDA, las donaciones se realizan según el tamaño o categorización de la empresa; en Perú, la Ley 30498 permite a todas las empresas de diversos tamaños y niveles de ingresos donar con los mismos requisitos, es decir, no existe una categorización de los mismos para poder efectuar la donación de alimentos.

\section{Comprobación de la hipótesis general}

Teniéndolos como hipótesis general, los beneficios tributarios señalados en la Ley 30498 funcionan positivamente como mecanismo de incentivo 
en la donación de alimentos de los supermercados en Lima Metropolitana, y al haberse definido ambas hipótesis específicas, se puede confirmar que la hipótesis general ha sido demostrada. Producto de ello se podrán crear a largo plazo más bancos de alimentos en Perú que serán construidos y puestos en funcionamiento a lo largo del país, combatiendo el hambre y contribuyendo así al segundo Objetivo de Desarrollo Sostenible - No hambre, con el apoyo directo de donaciones principalmente recibidas de supermercados ya que representan al mayor grupo con capacidad de donación de alimentos.

\section{Conclusiones}

La tributación en el Perú tiene una normativa que a lo largo de los últimos años ha empezado a vincularse más con la sociedad a la que rige; en ese sentido, el rol de la tributación, como herramienta estatal para contribuir a la construcción de metas programáticas sociales es fundamental, además de ser el mejor incentivo empresarial que empuja e invita a las empresas a involucrarse con las mismas. Por lo tanto a partir de la investigación se puede concluir lo siguiente:

1. Producto de la Ley 30498 , los beneficios disminuyen y optimizan la carga tributaria a los cuales la empresa procurará acogerse; por lo tanto, los supermercados se benefician en el aspecto tributario, y a su vez con las donaciones que realizan contribuyen a las necesidades humanitarias de las personas afectadas por falta de alimentos, a pesar de que su labor social es limitada por parámetros fiscales, no impide que la donación de alimentos aumente año tras año lo cual la ley respalda.

2. El incremento de las donaciones y la creación de los bancos de alimentos son promovidos a largo plazo desde la entrada en vigencia la Ley 30498, contribuyendo así con el segundo Objetivo de Desarrollo Sostenible - No hambre, logrando la distribución de alimentos en todo el Perú.

3. Producto de que la Ley 30498 fue comparada con el proyecto de Ley PDA, se concluye que el Perú puede tomar como ejemplo algunos criterios generales que abarca dicha proyecto, lo cual contribuirá a una visión más amplia para la 
ley de donación de alimentos, obtenida tras el análisis de selección de criterios que podrán aportar al régimen de donaciones en el Perú y viceversa.

\section{Recomendaciones}

Se recomienda al Estado peruano:

1. Suprimir los límites para la deducibilidad de los gastos destinados a donaciones de alimentos, ya que contribuyen a la atención de necesidades públicas.

2. Designar una partida presupuestal anual de apoyo con el objetivo de incentivar una mayor creación de bancos de alimentos en la capital y progresivamente en las provincias del país.

\section{Referencias}

Arteaga Ramírez, E. C. (2010). El derecho a la alimentación (tesis de grado). Escuela Superior de Administración Pública (ESAP), Bogotá D. C., Colombia.

Blondet, C. y Montero, C. (1995). Hoy: Menú Popular. Comedores en Lima. Lima, Perú: Instituto de Estudios Peruanos (IEP) y Fondo de Naciones Unidas para la Infancia (Unicef).

Constitución Política del Perú. (1993). Congreso de la República del Perú, Lima, Perú.

De Castro, J. (1951). Geopolítica da fomme. Río de Janeiro, Brasil: Casa do Estudante do Brasil.

Decreto Supremo 29. (1994). Reglamento de la Ley del Impuesto General a las Ventas e Impuesto Selectivo al Consumo. Diario Oficial El Peruano, Congreso de la República del Perú, Lima Perú, marzo de 1994.

Decreto Supremo 122. (1994). Reglamento de la Ley del Impuesto a la Renta. Diario Oficial El Peruano, Congreso de la República del Perú, Lima Perú, abril de 1994. Decreto Supremo 055. (1999). Reglamento de la Ley del Impuesto a la Renta. Diario Oficial El Peruano, Congreso de la República del Perú, Lima Perú, abril de 1999. Decreto Supremo 179. (2004). Texto Único Ordenado de la Ley del Impuesto a la Renta. Diario Oficial El Peruano, Congreso de la República del Perú, Lima Perú, diciembre de 2004. 
Hernández, M. (13 de septiembre de 2013). Un tercio de los alimentos que producimos en el mundo cada año acaba perdiéndose o en la basura. ElDiario. es. Recuperado de https://www.eldiario.es/desalambre/medio-ambiente/ alimentos-basura-medio_ambiente-desperdicio-FAO_0_174633404.html

Ley 29571. (2010). Código de protección y defensa del consumidor. Diario Oficial El Peruano, Congreso de la República del Perú, Lima, Perú, 1 de septiembre de 2010.

Ley 30948. (2016). Ley que promueve la donación de alimentos y facilita el transporte de donaciones en situaciones de desastres naturales. Diario Oficial El Peruano, Congreso de la República del Perú, Lima, Perú, 9 de agosto de 2016. Lizarzaburú, P. (1989). Asistencia alimentaria en el Perú. En Mujer y comedores populares, Nora Galer y Pilar Núñez (eds.), Lima, Perú: Sepade.

PerúRetail. (18 de enero de 2018). Ventas del sector retail en Perú crecieron 3.9 \% en el 2017, según CCL. Recuperado de https://www.peru-retail.com/ ventas-sector-retail-peru-crecieron-2017-segun-ccl/

Proyecto de Ley 169. (2016). Ley antidesperdicios contra el hambre en Colombia. Congreso de la República de Colombia, Bogotá D. C., Colombia, junio de 2016. Stang, S. (10 de diciembre de 2015). Donar para el bien común: requisitos del incentivo fiscal. Diario La Nación. Recuperado de www.lanacion.com.ar.

Villanueva Barrón, C. K. (2011). Los beneficios tributarios: exoneración, inafectación, entre otros Actualidad Empresarial, (238). Recuperado de http:// aempresarial.com/web/revitem/1_12813_62051.pdf

World Business Council for Sustainable Development. (1999). Corporate Social Responsibility: Meeting Changing Expectations. Nueva York: WBCSD. 